\title{
Mild Steel Corrosion Inhibition, in 4 N Sulphuric Acid, by a Green Inhibitor
}

\author{
Mahima Srivastava* \\ Department of Chemistry, DBS (PG) College, Dehradun - 248001, India
}

Received January 28, 2018; accepted May 10, 2018

\begin{abstract}
Use of Amaranthus extract, as mild steel corrosion inhibitor, in a pickling paste with $\mathrm{H}_{2} \mathrm{SO}_{4}$, has been investigated. The electrochemical experiments were conducted to bring forth results regarding various parameters, viz., corrosion current, anodic polarization and cathodic polarization. The corrosion current gradually decreased with time, for both uninhibited and inhibited systems. Polarization curves values indicate that Amaranthus extract adsorption modified anodic dissolution mechanism, as well as cathodic hydrogen evolution. From the results, it is clear that both cathodic and anodic reactions were inhibited, and that inhibition increased as the inhibitor concentration increased in acidic media, but the cathode was more polarized. This result indicated that Amaranthus extract can be classified as a cathodic inhibitor, in a $4 \mathrm{~N} \mathrm{H}_{2} \mathrm{SO}_{4}$ solution. Surface analysis via scanning electron microscope (SEM) showed a significant improvement on the mild steel plate surface morphology, in the presence of optimum inhibitor concentrations. Thus, by conducting these experiments, our aim is to use inhibited pickling acid in the paste form, so that it can be conveniently applied on large structures, as well as on small tools, to be pickled/cleaned. As a contribution to the current interest on environmentally friendly green corrosion inhibitors, the present study investigates the inhibiting effect of Amaranthus extract, a green inhibitor which is commonly known as Pigweed.
\end{abstract}

Keywords: Amaranthus extract, sulphuric acid, mild steel, polarization, SEM, corrosion, inhibitor.

\section{Introduction}

Iron and mild steel are used in large quantities for structural purposes, and for the fabrication of machine tools. Iron, on exposure to moist air, gets covered with a reddish-brown coating called rust. The rust essentially consists of hydrated ferric oxide, $\mathrm{Fe}_{2} \mathrm{O}_{3} .3 \mathrm{H}_{2} \mathrm{O}$, together with a small quantity of ferrous carbonate, $\mathrm{FeCO}_{3}$. Acid solutions are usually used for pickling, in order to remove rust from their surface. Results indicate that the metal dissolves most rapidly in a pure sulphuric acid solution, somewhat more slowly in pure hydrochloric acid and, slowest of

\footnotetext{
*Corresponding author. E-mail address: dr.mahima@ hotmail.com
} 
all, in pure phosphoric acid [1]. Iron dissolution in $\mathrm{H}_{2} \mathrm{SO}_{4}$ was slowed down by halide ions [2].

The hydrogen molecule, due to the slow rate of formation, in some cases, penetrates the crystal lattice and deforms it, leading to metal brittleness. Organic and inorganic inhibitors, or a mixture of both, can inhibit corrosion by either chemisorption, or by a reaction with metal ions, forming a barrier-type precipitate on the metal surface [3].

Many compounds have been reported as good corrosion inhibitors for mild steel, such as 4-methyl-4-H-1,2,4-Triazole-3-Thiol, 2-Mercaptonicotonic acid [4] and pyrimidothiazine [5], but, because of the toxic nature and/or high cost of some chemicals currently in use as inhibitors, it is necessary to develop environmentally acceptable and inexpensive substances. Natural products can be considered as a good source for this purpose. The aqueous extracts from different parts of some plants, such as henna, guar gum [6], neem leaves [7], Cucurbita maxima [8], Anacardium accidentale gum [9], juniperus [10] and papaya [11] have been found to be good corrosion inhibitors for many metals and alloys. Leaves extracts are used as common corrosion inhibitors. The anticorrosion activity of Citrus aurantifolia, bitter leaf root, Piper nigrum, Musa paradisica, and Nicotiana tabacum was investigated [12 - 16]. Corrosion inhibition has also been studied for the extracts of Beautiful swertia (Swertia angustifolia). Castor (Ricimus communis) leaves were studied for mild steel corrosion inhibition in acidic media, in addition to the use of herbs such as bread fruit, Ligularia fischeri, Phyllanthus amarus, palm oil and aloe vera gel, as new type of green inhibitors for steel acidic corrosion [17 - 21].

In the present work, our aim is to use inhibited pickling acid in the paste form, so that it can be conveniently applied on large structures, as well as on small tools, to be pickled / cleaned. As a contribution to the current interest on environmentally friendly green corrosion inhibitors, the present study investigated the inhibiting effect of Amaranthus extract, a green inhibitor which is commonly known as Pigweed (Fig. 1).

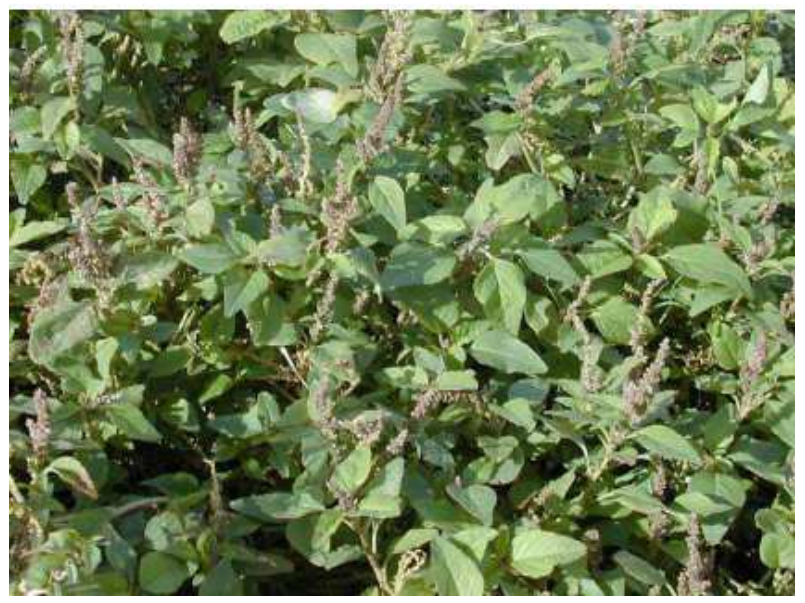

Figure 1. Amaranthus, commonly known as Pigweed. 


\section{Experimental}

Mild steel (Fe 99.30\%, C 0.076\%, Si 0.026\%, Mn 0.192\%, P 0.012\%, Cr $0.050 \%$, Ni $0.050 \%$, Al 0.023\%, and $\mathrm{Cu} 0.135 \%$ ) panels, with $10 \mathrm{~cm} \times 7.5 \mathrm{~cm}$ size, taken from pickled cold rolled closed annealed mild steel (18 SWG) cut from a single sheet, were used in all experiments. For specimens' identification, all were numbered, and a suspension hole of about $2 \mathrm{~mm}$ diameter near the upper edge was made. The specimens were polished to mirror finish, with emery paper. They were cleaned with cotton to remove powder and traces of adhered metal, and then they were degreased with sulfur-free toluene, followed by cleaning with methanol, before experiments. All the acid and chemicals used in the experiment were of AR grade quality. Distilled water was used for the solution preparation. Clay soil was collected, washed, dried, powdered and sieved. $100 \mathrm{~g}$ sieved soil were taken in a plastic glass with a hole at the bottom. This glass was put over uninhibited and inhibited acids. The soil uniformly soaked acid and, thus, the pickling paste was prepared. $100 \mathrm{~g}$ of soil soaked $31.3 \mathrm{cc}$ of acid. Polished and weighed panels were suspended by a V-shaped hook made of capillary tubes, with over $100 \%$ humidity, for 6 months, at room temperature. In 6 months, heavy rust appeared on the panels. The panels were re-weighed to estimate the rust amount. The pickling paste was applied over the weighed rusted panels under different conditions. After the experiment, the paste was removed by washing with a saturated sodium bicarbonate solution. The panels were again washed with water, and dried with hot air. The panels were finally weighed to estimate the amount of dissolved rust. Experiments were conducted in triplicate, and the mean value is reported in Table 1. Amaranthus leaves were crushed and squeezed. The thus obtained liquid was used as inhibitor. $1 \mathrm{cc}$ of the extracted liquid was added to $100 \mathrm{cc}$ of the acid, for the inhibited pickling paste preparation.

The corrosion current was measured using ammeters of $\mathrm{mA}$ range, by making galvanic couples of mild steel and platinum. The mild steel and platinum couple was put in the pickling paste (inhibited and uninhibited), and it was connected through the ammeter to record the corrosion current flowing through the couple. The corrosion current as a function of time was measured.

Table 1. Corrosion current in the steel-platinum couple placed in the paste $\left[4 \mathrm{~N} \mathrm{H}_{2} \mathrm{SO}_{4}\right.$; RT; Amaranthus $=1 \%]$.

\begin{tabular}{|c|c|c|}
\hline \multirow{2}{*}{$\begin{array}{c}\text { Time } \\
\text { (min.) }\end{array}$} & \multicolumn{2}{|c|}{ Current (mA) } \\
\cline { 2 - 3 } & Uninhibited & Inhibited \\
\hline 0 & 68 & 52 \\
\hline 10 & 65 & 48 \\
\hline 20 & 56 & 42 \\
\hline 30 & 52 & 35 \\
\hline 40 & 48 & 31 \\
\hline 50 & 47 & 27 \\
\hline 60 & 43 & 21 \\
\hline
\end{tabular}

Polarization measurements were made using a transistorized current source (CV/CC $30 \mathrm{~V}$-/A with a voltmeter and an ammeter), a 4 1/2 Digit Equitronics 
digital potentiometer, an Equitronics Digital Current Meter, a decade resistance box and a saturated calomel electrode.

The current was supplied from the power source through available resistance, and it was measured using a multimeter. Steel was used as working electrode, and platinum foil as auxiliary electrode.

The studied variables were the corrosion current and polarization (anodic and cathodic).

\section{SEM Analysis}

The surface morphologies of the uninhibited and inhibited mild steel in a $4 \mathrm{~N}$ sulphuric acid solution were investigated by scanning electron microscope (SEM). For SEM analysis, mild steel specimens were coated with a paste containing a $4 \mathrm{~N} \mathrm{H}_{2} \mathrm{SO}_{4}$ solution, in the absence and presence of optimum inhibitor concentrations, for a $24 \mathrm{~h}$ period. The mild steel specimens' surface morphology was examined by using a scanning electron microscope.

\section{Results and discussion}

\section{Corrosion current as a function of time for the mild steel-platinum couple}

A pickling paste with $4 \mathrm{~N} \mathrm{H}_{2} \mathrm{SO}_{4}$, with and without $1.0 \%$ Amaranthus, was prepared. Mild steel was connected to platinum, and both were placed in the pickling paste. Results given in Table 1 and Fig. 2 show that, in the uninhibited system, when steel was connected to platinum, the starting current was $68 \mathrm{~mA}$. The current gradually decreased with time. In the inhibited system, the starting current was $52 \mathrm{~mA}$, which gradually reduced to $21 \mathrm{~mA}$.

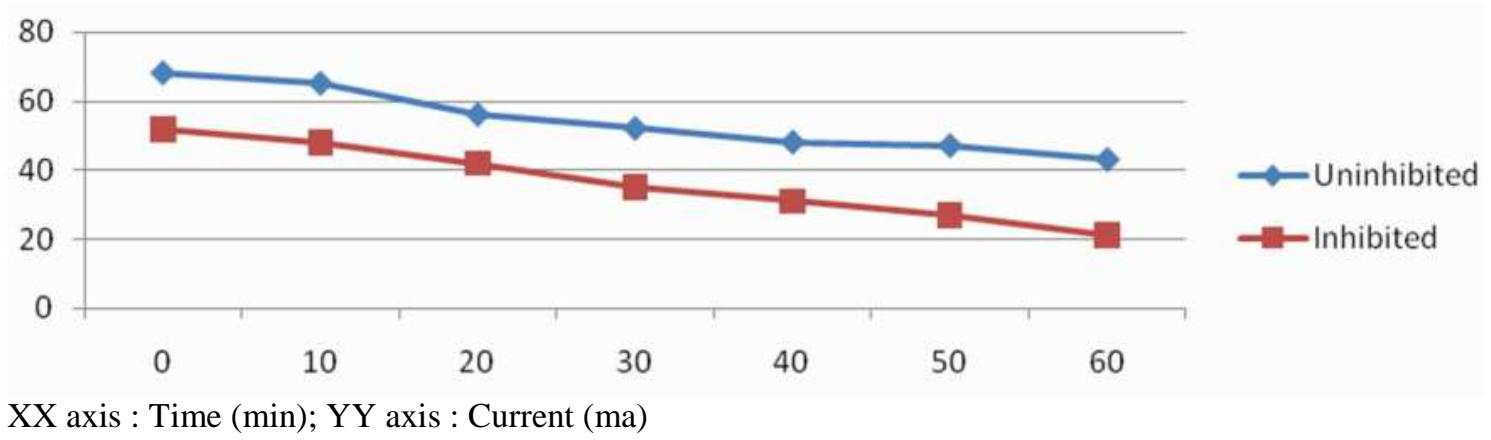

Figure 2. Corrosion current in the steel-platinum couple placed in the paste $[4 \mathrm{~N}$ $\mathrm{H}_{2} \mathrm{SO}_{4} ; \mathrm{RT} ;$ Amaranthus $\left.=1 \%\right]$.

\section{Mild steel polarization}

Anodic polarization

Table 2 and Fig. 3 show anodic polarization data for mild steel exposed to a pickling paste containing $4 \mathrm{~N} \mathrm{H}_{2} \mathrm{SO}_{4}$, with and without $1.0 \%$ Amaranthus. Results show that, when the current was raised from $3.2^{*} 10^{-3} \mathrm{~mA}$ to $47.8^{*} 10^{-3}$ $\mathrm{mA}$, the potential increased from $-580 \mathrm{mV}$ to $-544 \mathrm{mV}$, for the uninhibited system. In the inhibited system, the potential varied from $-575 \mathrm{mV}$ to $-519 \mathrm{mV}$. Thus, Amaranthus polarized the anode to some extent. 
Table 2. Anodic polarization data for mild steel placed in the paste [RT; $4 \mathrm{~N} \mathrm{H}_{2} \mathrm{SO}_{4}$; Amaranthus $=1 \%]$.

\begin{tabular}{|c|c|c|c|}
\hline $\begin{array}{c}\text { Current } \\
\text { density } \\
\left(\mathbf{m A} / \mathbf{c m}^{\mathbf{2}}\right)\end{array}$ & $\log \mathbf{C D}$ & $\begin{array}{c}\text { Uninhib. } \\
\text { potential } \\
(\mathbf{m V} \text { vs. SCE) }\end{array}$ & $\begin{array}{c}\text { Inhib. } \\
\text { potential } \\
(\mathbf{m V} \text { vs. SCE })\end{array}$ \\
\hline $3.2 \times 10^{-3}$ & -3.5051 & -580 & -575 \\
\hline $4.3 \times 10^{-3}$ & -3.6335 & -579 & -574 \\
\hline $6.4 \times 10^{-3}$ & -3.8021 & -578 & -572 \\
\hline $10.1 \times 10^{-3}$ & -2.0043 & -577 & -570 \\
\hline $15.0 \times 10^{-3}$ & -2.1761 & -575 & -568 \\
\hline $23.3 \times 10^{-3}$ & -2.3674 & -570 & -560 \\
\hline $31.7 \times 10^{-3}$ & -2.5011 & -560 & -551 \\
\hline $40.9 \times 10^{-3}$ & -2.6117 & -553 & -538 \\
\hline $47.8 \times 10^{-3}$ & -2.6803 & -544 & -519 \\
\hline
\end{tabular}

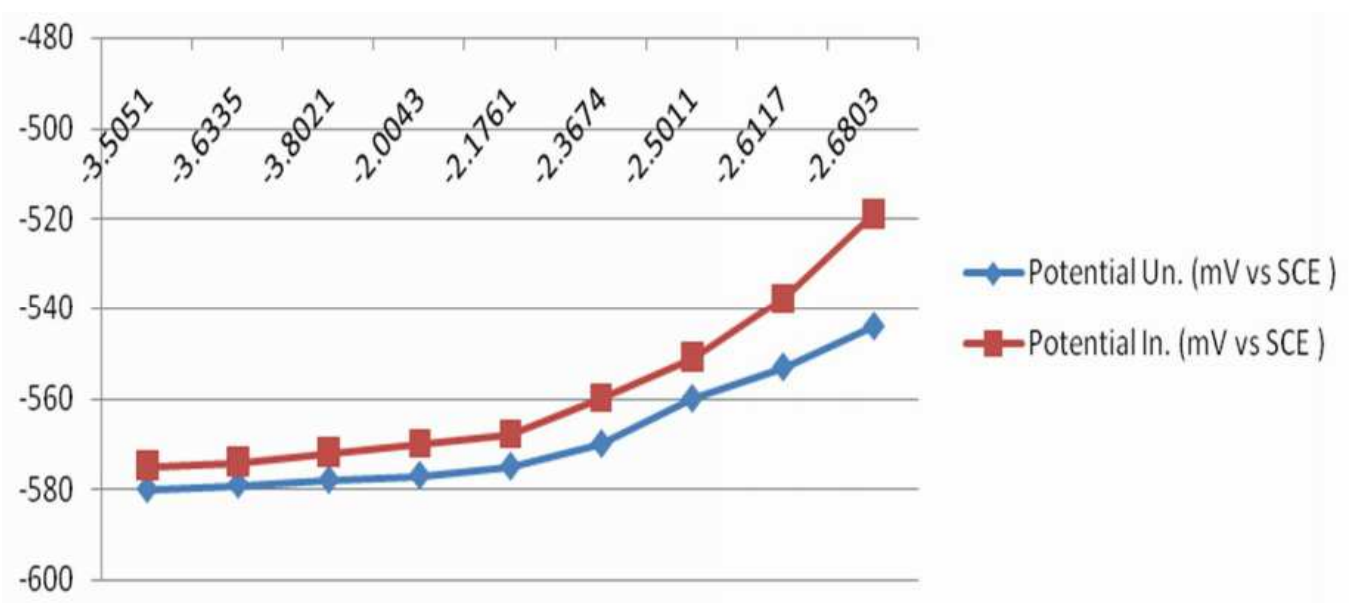

XX axis: $\log$ current density; YY axis: potential ( $\mathrm{mV}$ vs. SCE)

Figure 3. Anodic polarization data for mild steel placed in the paste [RT; $4 \mathrm{~N} \mathrm{H}_{2} \mathrm{SO}_{4}$; Amaranthus $=1 \%]$.

Table 3. Cathodic polarization data for mild steel placed in the paste [RT; $4 \mathrm{~N} \mathrm{H}_{2} \mathrm{SO}_{4}$; Amaranthus $=1 \%]$.

\begin{tabular}{|c|c|c|c|}
\hline $\begin{array}{c}\text { Current } \\
\text { density } \\
\left(\mathbf{m A} / \mathbf{c m}^{2}\right)\end{array}$ & $\begin{array}{c}\text { log } \\
\text { CD }\end{array}$ & $\begin{array}{c}\text { Uninhib. } \\
\text { potential } \\
(\mathbf{m V} \text { vs. } \\
\text { SCE) }\end{array}$ & $\begin{array}{c}\text { Inhib. } \\
\text { potential } \\
(\mathbf{m V} \text { vS. } \\
\text { SCE) }\end{array}$ \\
\hline $1.2 \times 10^{-3}$ & - & -510 & -530 \\
\hline $1.7 \times 10^{-3}$ & -3.233 & -510 & -533 \\
\hline $2.5 \times 10^{-3}$ & - & -512 & -537 \\
\hline $4.1 \times 10^{-3}$ & - & -513 & -544 \\
\hline $5.9 \times 10^{-3}$ & - & -514 & -551 \\
\hline $8.1 \times 10^{-3}$ & -3.909 & -516 & -560 \\
\hline $9.2 \times 10^{-3}$ & - & -520 & -572 \\
\hline $12.8 \times 10^{-3}$ & - & -523 & -579 \\
\hline $15.6 \times 10^{-3}$ & - & -525 & -587 \\
\hline
\end{tabular}

\section{Cathodic polarization}

Table 3 and Fig. 4 show cathodic polarization data for mild steel exposed to a pickling paste containing $4 \mathrm{~N} \mathrm{H}_{2} \mathrm{SO}_{4}$, with and without $1.0 \%$ Amaranthus. Results show a potential drop, when the current was raised from $1.2 \times 10^{-3} \mathrm{~mA}$ to 
$15.6 \times 10^{-3} \mathrm{~mA}$, for the uninhibited system. For the inhibited system, at minimum current density $\left(1.2 \times 10^{-3} \mathrm{~mA} / \mathrm{cm}^{2}\right)$, the potential was $-530 \mathrm{mV}$, which decreased to $-587 \mathrm{mV}$, at maximum current density $\left(15.6 \times 10^{-3} \mathrm{~mA} / \mathrm{cm}^{2}\right)$. Thus, a potential $\Delta \mathrm{V}$ drop, of $57 \mathrm{mV}$, was observed, suggesting that Amaranthus polarized the cathode to a considerable extent.

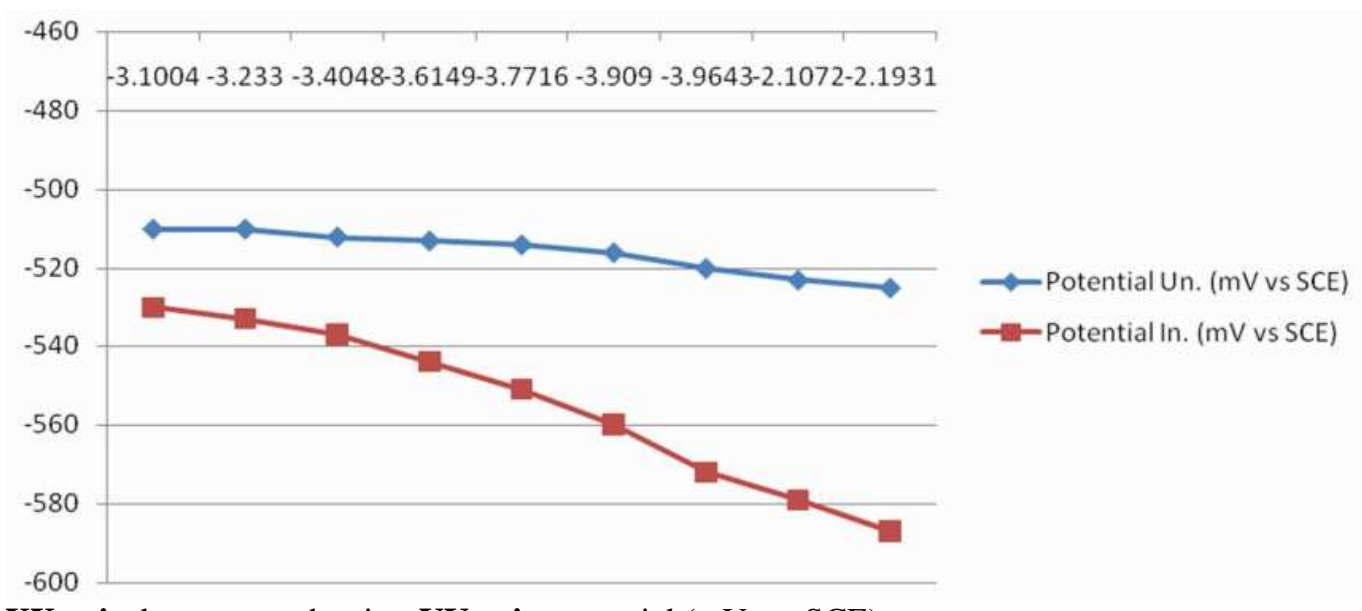

XX axis: $\log$ current density; YY axis: potential ( $\mathrm{mV}$ vs. SCE)

Figure 4. Cathodic polarization data for mild steel placed in the paste [RT; $4 \mathrm{~N}_{2} \mathrm{SO}_{4}$; Amaranthus $=1 \%]$.

\section{SEM Analysis}

SEM analysis was recorded for the mild steel surface immersed in the paste with an acidic solution, in the inhibitor absence and presence, to prove Amaranthus extract interactions with the mild steel surface [1]. Fig. 5a shows the SEM image of the mild steel surface before immersion in the $4 \mathrm{~N} \mathrm{H}_{2} \mathrm{SO}_{4}$ solution, whereas Figs. $5 \mathrm{~b}$ and c show the mild steel surface that was immersed in the $4 \mathrm{~N}_{2} \mathrm{SO}_{4}$ solution, in the inhibitor absence and presence, for $24 \mathrm{~h}$, respectively. According to Fig. 5b, the mild steel surface severely corroded in the inhibitor absence. On the other hand, no corrosion could be observed in the case of the mild steel sample immersed in the inhibited solution, at optimum inhibitor concentrations (Fig. 5c). In general, less damage to the surface can be seen in the Amaranthus extract presence, indicating that the inhibitor compounds are stable in a $4 \mathrm{~N}$ $\mathrm{H}_{2} \mathrm{SO}_{4}$ solution, and able to provide an effective corrosion inhibition of the mild steel surface [3].
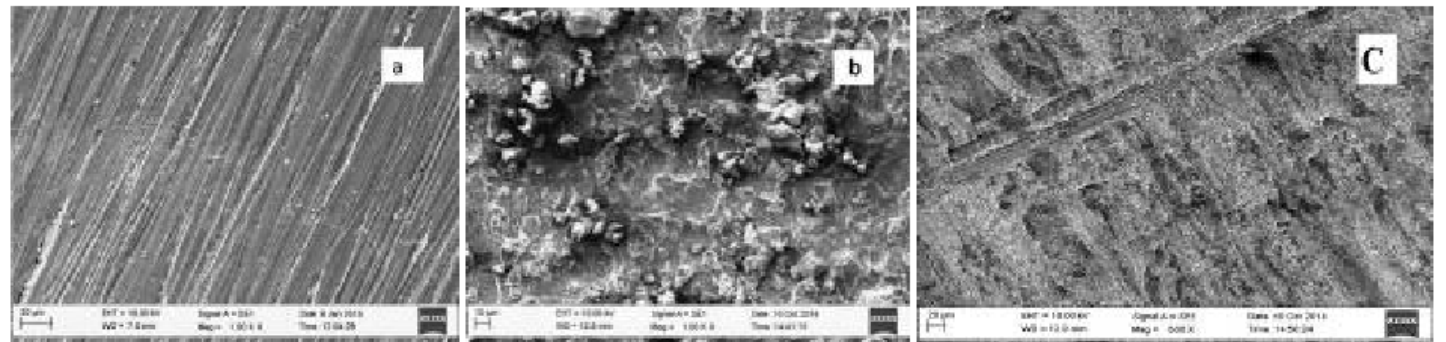

Figure 5. SEM images of (a) mild steel, (b) mild steel in $4 \mathrm{~N} \mathrm{H}_{2} \mathrm{SO}_{4}$, and (c) mild steel in the inhibitor presence, for a $24 \mathrm{~h}$ period. 


\section{Conclusion}

All measurements showed that Amaranthus extract has excellent inhibition properties for mild steel corrosion in a $4 \mathrm{~N} \mathrm{H}_{2} \mathrm{SO}_{4}$ solution. Amaranthus leaves extract adsorption is uniform over the surface. The inhibition is due to the film formation onto the metal/acid solution interface, through the adsorption of Amaranthus leaves extract molecules. Amaranthus polarizes the cathode, thus acting as a cathodic inhibitor. SEM micrographs show that the protective layer formed over the metal surface prevents further corrosion. The chemical composition of Amaranthus contains higher alkanes and their methyl derivatives, higher aliphatic alcohols, acids and esters, amino acids, $\beta$-sitosterol, stigmasterol, campesterol, cholesterol, $\alpha$-spinasterol, glycosides of $\alpha$-spinasterol, oleanoic acid, quercetin, rutin, $\alpha$-spinasterol octacosanoate. A new saponin- $\beta$-D-glucopyranosyl (1-4)- $\beta$-D-glucopyranosyl (1-4)- $\beta$-D-glucurono-pyramosyl(1-3)-oleanolic acid(I) has been isolated from the plant.

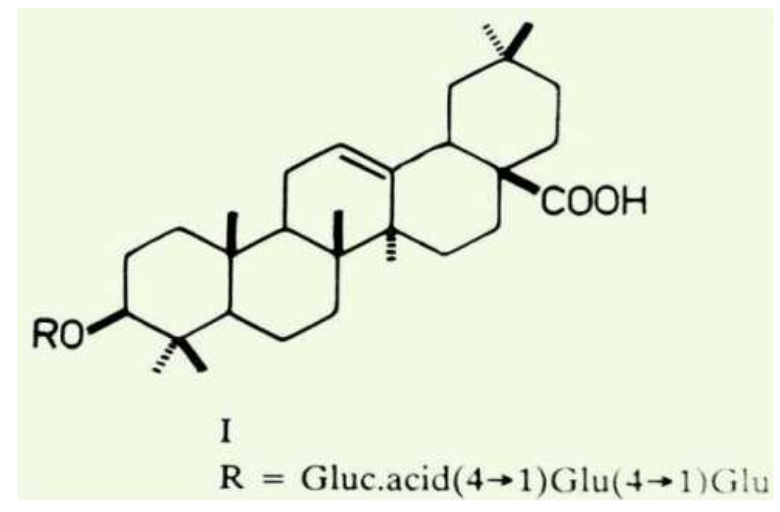

\section{Acknowledgments}

My sincere thanks to the Department of Chemistry, DBS (PG) College, Dehradun, India, for allowing me to use their resources.

\section{References}

1. Putilova N, Balezin SA, Barannik VP. Metallic Corrosion Inhibitor. New York: Pergamon Press; 1960. pp 104-110.

2. Srivastava K, Sanyal B. Labdev J Sci Technol. 1970;8-A:104.

3. Srivastava K, Srivastava P. British Corros J. 1981;16:221.

4. Mehmeti VV, Berisha AR. Front Chem. 2017;5:61.

5. Larouj M, Lgaz H, Sarghi R, et al. Anal Bioanal Electrochem. 2018;10:3351.

6. Roy P, Karfa P, Adhikari U, et al. Corros Sci. 2014;88:246-253.

7. Tuaweri TJ, Ogbonnaya EA, Onyemaobi OO. Int J Res Eng Technol. 2015;4:404-409.

8. Anbarasi K, Vasudha VG. Chem Sci Rev Lett. 2014;3:45-51.

9. Arthur DE, Adedayo A, Igelige G, et al. Am Chem Sci J. 2014;4:847-854.

10. Al-Mhyawi SR. African J Pure Appl Chem. 2014;8:9-22. 
11. Ajani KC, Abdulrahman AS, Mudiare E. World Appl Sci J. 2014;31:21412147.

12. Kavitha N, Manjula P, Anandha N. Res J Chem Sci. 2014;4:88-93.

13. Caroline AI, Abdulrahaman AS, Kobe IH, et al. Am J Mater Eng Technol. 2015;3:35-45.

14. Mohd N, Ishak AS. Indian J Sci Technol. 2015;8:63478.

15. Ji G, Anjum S, Sundaram S, et al. Corros Sci. 2015;90:107-117.

16. Bhawsar J, Jain PK, Jain P. Alexandria Eng J. 2015;54:769-775.

17. Ejikeme PM, Umana SG, Menkiti MC, et al. Int J Mater Chem. 2015;5:1423.

18. Prabakaran M, Kim S-H, Kalaiselvi K, et al. J Taiwan Inst Chem Eng. 2016;59:553-562.

19. Anupama KK, Ramya K, Joseph A. J Mol Liq. 2016;216:146-155.

20. Hussin MH, Rahim AA, Ibrahim MNM, et al. Measurement. 2016;78:90103.

21. Singh AK, Mohapatra S, Pani B. J Ind Eng Chem. 2016;33:288-297. 